\title{
The Influence of Train Type, Car Weight, and Train Length on Passenger Train Crashworthiness
}

\author{
Michelle Priante \\ David Tyrell \\ Volpe National Transportation Systems Center \\ US Department of Transportation \\ Cambridge, MA 02142 USA \\ Benjamin Perlman \\ Tufts University \\ Medford, Massachusetts
}

\begin{abstract}
Crash energy management (CEM) is a type of equipment design that is intended to protect occupant space during a collision. Structures at the front and back of each car act as crumple zones that absorb the collision energy. CEM is intended to distribute the damage from a collision throughout a consist to unoccupied areas. This paper describes how factors that vary in the operation of passenger trains affect the crashworthiness performance of conventional and CEM trains.

Crush and secondary impact velocity are introduced as measures of crashworthiness performance. The collision scenario selected for this study includes a standing locomotiveled freight train and a cab led passenger train with an initial velocity. The passenger train contains either all CEM or all conventional equipment, and is either a multiple unit (MU) train with no locomotive, or push-pull train. The influence of consist type (MU or push-pull,) car weight, and the number of cars in a train-to-train crashworthiness are explored.

The crashworthy speed is that speed at which all of the passenger train occupants are predicted to survive in the selected collision scenario. For both conventional and CEM equipment, MU trains have slightly higher crashworthy speeds than push-pull trains. Trains with heavier cars have lower crashworthy speeds for both conventional and CEM equipment. Longer trains also have lower crashworthy speeds, although the decrease crashworthy speed is less for CEM trains than for conventional trains. In all cases evaluated, the CEM trains have significantly higher crashworthy speed than the conventional trains; the crashworthy speed of CEM trains is typically twice that of conventional trains, and in some cases is nearly three times greater.
\end{abstract}

\section{INTRODUCTION}

The work for this paper is done under the Federal Railroad Administration's Equipment Safety Research Program. The goal of the rail passenger equipment crashworthiness research conducted under this program is to propose strategies for improving occupant protection in train accidents. The research approach involves determining the accident scenarios of concern, evaluating the performance of existing equipment in those scenarios, proposing and evaluating the effectiveness of alternative designs, and comparing the effectiveness of the conventional and alternative equipment. The effectiveness of conventional and alternative equipment is evaluated both with analyses and tests.

This paper builds directly on three previous studies $[1,2$, and 3]. In the first study, the crashworthiness performance of CEM equipment was compared with the performance of conventional equipment in locomotive-led passenger train-tolocomotive-led passenger train collisions. This study concluded that the crashworthiness performance of CEM equipment surpassed that of conventional equipment in higher speed collision (with closing speeds greater than $70 \mathrm{mph}$ ) and that the crashworthiness performance was similar in lower speed collisions, for two locomotive-led passenger trains colliding head-on. Subsequently, modeling of the crush behavior of conventional equipment was performed [4], which showed that the force required to crush a conventional rail passenger car dropped substantially after the car had been crushed by less than one foot. In the initial study, this force had been assumed to reach a high level and remain at that high level for at least six feet of crush. The analysis of the crush behavior of conventional equipment was confirmed with fullscale tests [5].

The crashworthiness performance of conventional cab car led trains in a collision with a locomotive-led train was 
evaluated in the second study [2]. In that study, it was found that the crashworthiness performance of CEM equipment exceeded that of conventional equipment in such collisions for closing speeds greater than $13 \mathrm{mph}$. The CEM force/crush characteristic evaluated in this study resulted in preserving the space for all the occupants for collision speeds up to $30 \mathrm{mph}-$ more than twice the speed of conventional equipment. This study established that CEM equipment can potentially increase the crashworthiness of cab car-led passenger trains in train-totrain collisions for a wide range of collision speeds.

The third study [3] addressed some of the potential concerns of putting CEM equipment into service. Since rail passenger equipment has a service life in the range of 30 years or more, any new CEM equipment would necessarily be operated mixed with conventional equipment. The study results presented in this paper give a better understanding of how to best utilize CEM equipment with conventional equipment. If one CEM car is available, it should be used as the cab car at the end of the consist. Placement of a single CEM car anywhere else in the consist is not beneficial because a conventional cab car does not transmit any crush to the trailing cars, whether the trailing cars are CEM or conventional equipment. Putting one or more CEM cars behind a conventional cab car does not improve crashworthiness, but it also does not degrade crashworthiness. The crashworthiness performance of a consist which is a mix of conventional and CEM equipment is never worse than the performance of an all conventional equipment consist in a trainto-train collision, and is always better when a CEM car is the impacted cab car.

The collision scenario investigated in the study described in this paper is a passenger train-to-freight train in-line collision. Two different types of passenger trains are considered: a multiple-unit (MU) train, in which the cars are self-propelled, and a push-pull train which has a locomotive at one end and a $\mathrm{cab}$ car at the other. The performances of conventional equipment and crash energy management (CEM) equipment are evaluated and compared. CEM is intended to distribute the damage from a collision throughout a consist to unoccupied areas. Structures at the front and back of each car act as crumple zones that absorb the collision energy.

This paper describes how train parameters affect the performance of conventional and CEM equipment in passenger-to-freight train collision. In addition to the influence of train type (MU or push-pull,) the influence of car weight and train length on train crashworthiness are also determined.

\section{DESCRIPTION OF APPROACH}

A one-dimensional model is used to compare lost occupant volume and the impacts of occupants with the interior for the two structural crashworthiness strategies. In this model, each car has its own degree-of-freedom. This model is similar to those used in the three previous studies, and results of such a model have been shown to correlate closely with train-to-train test measurements [6].

Inputs into the model include the force/crush characteristics of the cars, the weight of the cars, and the number of cars. CEM and conventional passenger cars have the same weight, but very different force/crush characteristics.

Key results from the model include the distribution of crush among the cars of the train, and the secondary impact velocity, which refers to the impact between the occupant and some part of the interior, usually the forward seat, table or bulkhead. Secondary impact velocity is the relative velocity difference between the occupant and the rail car itself at the point of impact. The car crush and secondary impact velocities are used to determine the maximum collision speed at which no fatalities would occur.

In order for passengers to survive a collision, their occupant volume must be preserved and they must have survivable secondary collision conditions. The safety of passengers is measured by crashworthy speed, the maximum speed that a train can go without any passenger fatalities. While crashworthy speed is the eventual goal of CEM trains, this paper looks to gain a better understanding of energy distribution in CEM consists under different operating collisions.

\section{Structural Design Characteristics}

Conventional structure describes the design of current rail vehicles in North America. Passenger trains or consists are assembled with combinations of three types of cars: a locomotive, coach cars and a cab car with an operator and passengers. Cab car led trains present a challenging situation in collisions. The presence of the operator and passengers in the cab car as well as lighter weight of the cab car in comparison with locomotives exposes cab cars to the most risk. A locomotive has a very strong structure that typically absorbs little energy during a collision. As a result, most of the energy dissipation will take place in the cab car of the cab car leading train, where an operator and passengers are located.

What distinguishes the conventional structure from CEM design is the force necessary to crush a car. Figure 1 shows a simplified version of the force-crush behavior based on tests of conventional vehicles $[5,6]$.

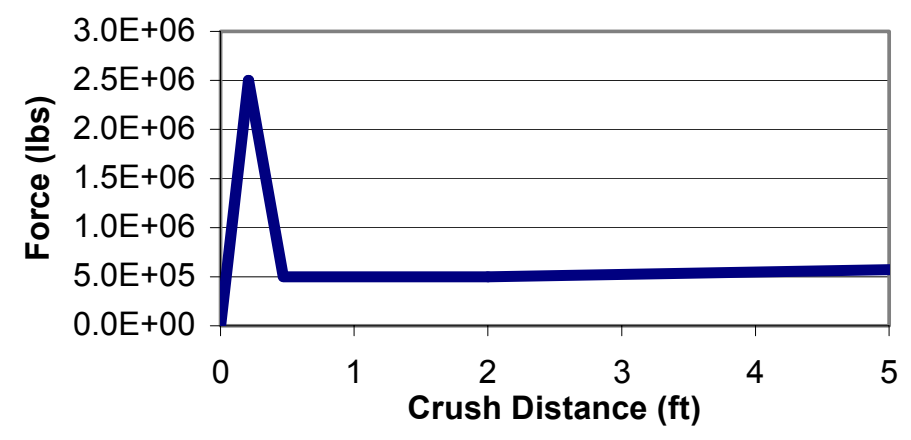

Figure 1. Force/Crush Curve for a Conventional Train

Shown in Figure 2 is a top view schematic of a typical single level passenger car structure. The black lines indicate the frame of the car. The length of the car is approximately 85 feet. The coupler is pushed back with little force. The draft sill is a strong structural member designed to take high longitudinal force. The draft sill and the end of the car both fail under dynamic load at approximately 2.5 million pounds, as shown in the force crush curve.

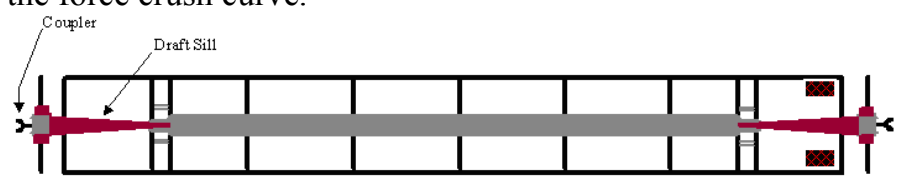

Figure 2. Top View Schematic of Passenger Car Structure 
A large force is required to crush the end of the car the first six inches. This large force buckles the draft sill. Once the draft sill buckles, the rest of the car crushes at a much lower force level. In any train collision involving a cab led passenger train, the majority of the crush is typically focused on the front end of the leading cab car. In this situation the first half-foot of the car will be crushed under the enormous force of the collision, leaving the front end of the cab car with weak protection.

In a train collision, the crushing of the end structures controls the deceleration of the train. Speed and kinetic energy are reduced when the end structure is crushed. The CEM structure aims to control the energy dissipated in a collision, allowing for more car ends to be crushed while preserving passenger space. Energy is the product of force and distance, so in a force versus crush distance graph, energy is the area under the force-crush curve. In both cars the 3.25 foot crush zone on the end of the car is not occupied by passengers. It is apparent from Figure 3, an illustration of CEM behavior, that there is more area under the force crush curve of the CEM car than the conventional car in the first 3.25 feet. The CEM train absorbs 4.44 MJ $\left(3.28 \times 10^{6} \mathrm{ft}-\mathrm{lbs}\right)$ of energy in the first 3.25 feet, whereas the conventional car absorbs only $2.8 \mathrm{MJ}\left(2.07 \times 10^{6} \mathrm{ft}-\right.$ lbs) of energy in the same crush distance.

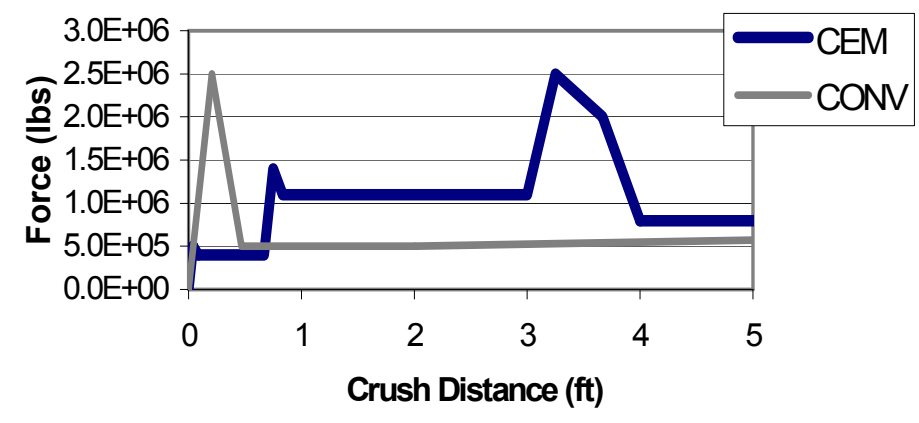

Figure 3. Force crush characteristics for the conventional and CEM trains

The difference is that in a CEM consist, the ends of the cab and coach cars have been constructed to increase the collision force as more of a car is deformed. This strategy is carried out through sacrificial crush zones at either end of each car. The crush zones are similar in concept to the crumple zones on a car. In the Federal Railroad Administration (FRA) research program CEM cars are retrofitted with crush zones. New car designs incorporating CEM can also be designed. The CEM force crush concept can be viewed as a series of steps, as shown in Figure 3. The CEM curve used for this study is a specific design suggested in [3]. There are other design possibilities that would have the necessary force/crush behavior. This force crush curve reaches the same peak force value as the conventional train at a distance of 3 feet. The coupler and the draft gear are identical to existing equipment.

The first step in this force crush curve represents the coupler. It crushes at a force of $4 \times 10^{5} \mathrm{lbs}$, large enough for service operation. After the coupler bolts fail in shear, a honeycomb structure crushes as the pushback coupler module slides back. The pushback coupler module is shown in Figure 4. The next peak in the CEM curve is the sliding sill shear bolts. The bolts are designed to shear at a force of $1.4 \times 10^{6} \mathrm{lbs}$. Following the fracture of the sliding sill shear bolts, the front structure slides back, crushing the primary energy absorbers and the roof energy absorbers. These energy absorbers crush at a force of approximately $1.1 \times 10^{6} \mathrm{lbs}$. Behind the energy absorber structure, approximately 3.25 feet from the front of the car, is the strong occupant compartment. The occupant compartment is assumed to crush at a high peak of $2.5 \times 10^{6} \mathrm{lbs}$. Similar to the conventional train, once this peak is surpassed, crushing proceeds at a relatively low force.

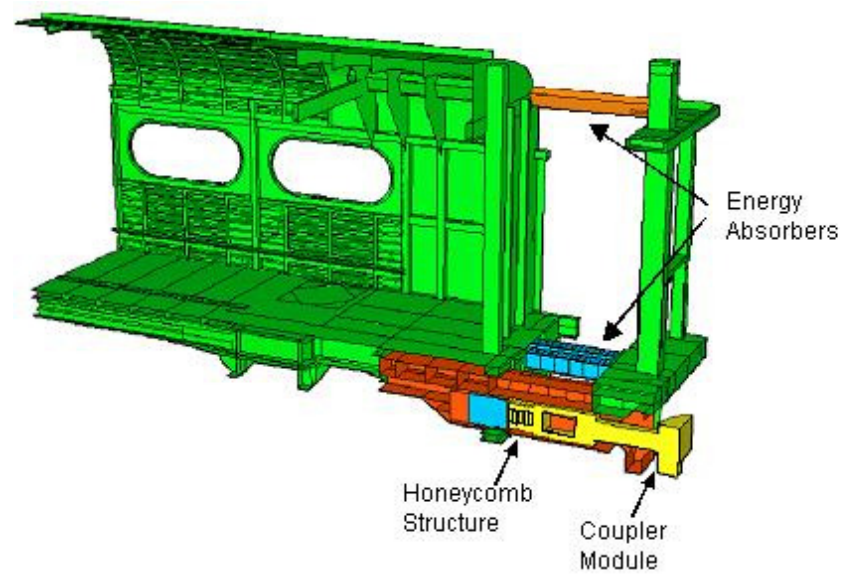

Figure 4. Finite Element Model of the Overall Coach Car Crush Zone Design (Half Model)

Part of the CEM strategy is that crush occurs at multiple interfaces. In the conventional train, the front end of the first car crushes, often into the occupant compartment. In the CEM train, each crush zone not only absorbs energy, but also allows for each car to undergo its own collision. As a result, more energy is absorbed at unoccupied compartments throughout the consist. By spreading crush absorption through a consist, occupant space is more likely to survive.

\section{Collision Scenario}

To improve the understanding of CEM strategy, further studies examine variables found in the routine operation of passenger trains. These computer analyses involved a collision between a freight train and a passenger train. In the previous studies on CEM trains, the passenger trains collided with similar passenger trains. In some areas of the country, however, passenger trains run on the same tracks as freight trains. Freight trains carry heavy loads and can be up to a mile long. Larger freight trains may have multiple locomotives pulling the cargo. In the research done for this paper, a freight train was chosen as the intercepting train. The numbers given for crashworthy speed in these results are synonymous with a passenger train running into a wall. In passenger train to passenger train collisions, crashworthy speed would be higher than in this worst-case scenario.

In this study a moving cab led passenger train has an initial velocity when it collides with a standing freight train. The freight train model is based in the model developed to analyze the Placentia freight train-to-passenger train collision [7]. Each scenario has a passenger train with a specific velocity, a certain length, a certain weight and either a CEM or a conventional cab and coach cars. In each scenario the passenger train is either an MU consist with no locomotive or a push-pull train. 


\section{Train Parameters}

The following train parameters were analyzed: train type, train length, and car weight. These analyses were performed using the matrix described in Table 1 . The first train type analyzed is a push-pull train. The length of the train is varied while the weight is held constant. Under these conditions the crashworthy speed of the CEM is compared with the crashworthy speed of the conventional train. Then the weight of the cars is varied while the length is held constant and the CEM and conventional consists are compared. After the length and the weight are examined separately, the variations are combined for an overall comparison.

The second type of train analyzed is an MU train, which has no locomotive car. The same variables are analyzed for MU trains. The length is varied while the weight is held constant. Then the weight is varied while the length is held constant. Then the two variables are combined to give an overall look at crashworthy speed in CEM and conventional trains.

Table 1. Analysis Matrix

\begin{tabular}{|c|c|}
\hline Factor & Variations \\
\hline Train Type \#1 & Push-Pull \\
\hline Train Length & 2 Coach Cars \\
& 4 Coach Cars \\
& 6 Coach Cars \\
\hline Car Weight & 75 Kips \\
& 100 Kips \\
& 125 Kips \\
& 150 Kips \\
\hline Train Type \#2 & MU \\
\hline Train Length & 2 Coach Cars \\
& 4 Coach Cars \\
& 6 Coach Cars \\
\hline Car Weight & 75 Kips \\
& 100 Kips \\
& 125 Kips \\
& 150 Kips \\
\hline
\end{tabular}

\section{Determining Crashworthy speed}

When a train is in a collision, there are two measures used to estimate the fatality rate. If there is a large amount of crush, then passenger volume is lost. Loss of passenger volume means there will be near certain fatalities. If the train undergoes high decelerations, the passengers may encounter severe secondary collisions with the interior of the car. CEM trains have increased deceleration, particularly in the front car. These increased decelerations result in greater risk of injury.

The first measure of crashworthiness is the amount of occupant space left. Each passenger is assumed to be sitting in a seat, and all the seats are assumed to be filled. When the end of a train is crushed, the volume of the train crushed during the collision is lost, along with an additional portion of volume that contains the displaced material. We assume that crushed material takes up an additional $40 \%$ of passenger space. In a typical coach car, passengers are seated 3-4 feet from either end of the train. When 4 feet of the car have been lost, the first row of passenger seats is vulnerable. At very high collision speeds, where much passenger volume is lost, the longitudinal spacing between rows of seats (seat pitch) must be taken into account to determine the number of rows affected.
The second measure of fatality rate comes from the secondary collision when a passenger hits a surface in the interior of the car. While there is not enough data in the train industry to calculate injury criteria, the automotive industry has well thought out and readily available injury standards for collisions. The automotive industry has injury criterion used to define the severity of a secondary collision. There are injury criteria for the neck load, head, and chest decelerations. The standards used in this paper are not the only possible standards for use in train collisions.

The injury indices used in the automotive industry can be correlated to injuries in train collisions by measuring the secondary impact velocity. The Secondary Impact Velocity (SIV) is the speed that the head is going relative to the train when the head collides with the seat in front. At an SIV of 20 $\mathrm{mph}$, it is estimated that all the passengers in the train will survive. This is a simplified method for measuring the complicated problem of injury. It should also be noted that measures can be taken to lower the SIV. The seats can be rearward facing, the passengers can wear seatbelts, and the characteristics of the seats can be changed.

\section{RESULTS}

\section{Push-Pull Trains}

In the push-pull trains in the study, there is a leading cab car followed by a varying number of coach cars and pushed by a locomotive. The cab car structure is lighter and less rigid than the locomotive. Additionally, there are passengers sitting in the cab car, often no more than 4 feet from the front of the train. Thus, by setting safety standards for a cab leading train, the locomotive leading trains are automatically protected. The variations used in analyzing push-pull trains are shown in Table 2.

Table 2. Analysis Matrix for Push-Pull Trains

\begin{tabular}{|c|c|}
\hline Factor & Variations \\
\hline Train Type \#1 & Push-Pull \\
\hline Train Length & 2,4, or 6 Coach Cars \\
\hline Car Weight & $75,100,125$, or 150 Kips \\
\hline
\end{tabular}

\section{Push-Pull Trains: Consist Length}

In practice, trains are not all the same length. Depending on the route and the time of day, the numbers of cars in a consist will vary. In this study the smallest number of cars in a pushpull train is 4: a cab car, 2 coach cars and a trailing locomotive. Trains can be very long with numerous coach cars. Ideally, a longer consist would be able to crush up to 4 feet at each interface and would be able to resist crushing passenger space. An obvious trade off for the extra sacrificial space gained by adding cars is a heavier consist and higher kinetic energy in the crash. Shorter trains have less mass and therefore less kinetic energy in a collision, but also have less sacrificial crush areas. In these trials, the weight is held constant at 100 Kips per coach or cab car.

This study looked at trains at three different length increments. Shown in Table 3 is the matrix used to analyze train lengths. 
Table 3. Analysis Matrix for push-pull trains with varying lengths

\begin{tabular}{|l|l|l|l|}
\hline $\begin{array}{l}\text { Consist } \\
\text { Length }\end{array}$ & \multicolumn{3}{c|}{ Consist make-up } \\
\hline 4 Car: & 1 Cab Car & 2 Coach Cars & 1 Trailing Locomotive \\
\hline 6 Car: & 1 Cab Car & 4 Coach Cars & 1 Trailing Locomotive \\
\hline 8 Car: & 1 Cab Car & 6 Coach Cars & 1 Trailing Locomotive \\
\hline
\end{tabular}

Longer trains have more cars and therefore a higher total weight than shorter trains. This higher weight means that a longer train has more kinetic energy than a shorter train with the same initial velocity. The higher energy heading into the collision means that the train will have to dissipate more energy. In a train collision, the majority of this energy is absorbed by crushing the train structure. The results shown in Figure 5 demonstrate that longer trains tend to have lower maximum crashworthy speed than shorter trains. When looking at crashworthy speed due to crush, conventional and CEM trains behave differently. In the CEM trains, consist length has comparatively minor influence on the maximum crashworthy speed of push-pull trains. The crashworthy speed varies by less than $1 \mathrm{mph}$ when 4 cars are added onto a consist.

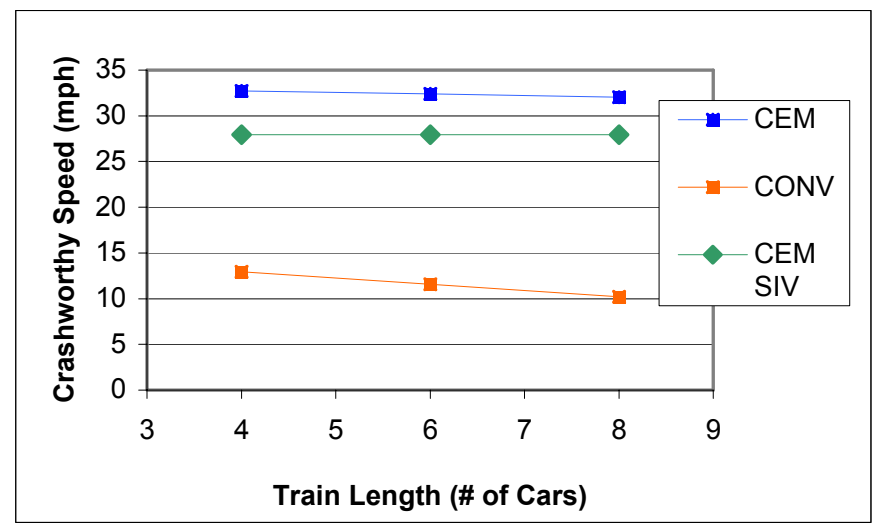

Figure 5. The effect of train length on maximum crashworthy speed for push-pull trains

Changes in train length have a slightly greater impact on the conventional trains. Conventional trains only crush in one location, the front end of the leading car. Adding on additional cars does not help to absorb extra energy. Extra cars in a conventional train only add mass to the train and therefore there is more kinetic energy leading into the crash. In the push-pull trains, the crashworthy speed decreases as train length increases. The maximum crashworthy speed decreases $3 \mathrm{mph}$, from $13 \mathrm{mph}$ to $10 \mathrm{mph}$, between a 4 car consist and an 8 car consist for a conventional train. In CEM trains crashworthy speed decreases $0.7 \mathrm{mph}$, from $32.7 \mathrm{mph}$ to $32 \mathrm{mph}$, between a 4 car consist and an 8 car consist.

As noted before, there are two criteria for survival in a train crash. Already discussed is the effect of train length on crashworthy speed due to crush. Next shown is the effect of train length on the secondary impact velocity (SIV) felt by the passengers. For the CEM trains, the maximum crashworthy speed due to SIV is lower than the crashworthy speed due to crush. For conventional trains, the SIV is not a factor because passenger space is lost at a lower speed than the speed at which SIV becomes a factor. When SIV is taken into account in CEM trains, the maximum crashworthy speed is lowered by about 6 $\mathrm{mph}$. The SIV is not affected by train length in this scenario. Even with SIV taken into account, it is still safer to be in a CEM consist than a conventional consist because the crashworthy speed for the CEM consists is higher.

\section{Push-Pull Trains: Consist Weight}

In practice not all trains have the same weight. The weight of a car depends on how many people are riding in the car, how much luggage they are carrying, and the weight of the equipment inside the car. This part of the study compares the reaction of a CEM consist to a conventional consist with an increase in weight. In these results, the train length is held constant at 6 cars: 1 cab, 4 coach and 1 trailing locomotive. If the train is a $75 \mathrm{Kip}$ consist, this means that the cab cars and coach cars in the train weight $75 \mathrm{Kips}$ each. The locomotive weight is held constant at $263 \mathrm{Kips}$. A heavier car means higher kinetic energy. When there is more energy in a collision, more energy must be dissipated by crushing the cars.

This study looked at cars that each weighed $75,100,125$, or 150 Kips. The influence of car weight on crashworthy speed is shown in Figure 6. The passenger trains are composed of either all CEM passenger cars or all conventional passenger cars. The passenger train has an initial velocity, and it collides with the standing freight train model described earlier. In this section, a six-car train is used to demonstrate the effect of car weight on crashworthy speed. When looking at crashworthy speed due to crush in the six car consist, weight has a greater effect on CEM consists than on conventional consists. Passengers are not exposed to greater risk when they are traveling in a CEM car, even if the CEM car is running at a heavier weight than normal. The crashworthy speed drops $7 \mathrm{mph}$ from $35 \mathrm{mph}$ to $28 \mathrm{mph}$ between the lightest CEM consist and the heaviest CEM consist. On the other hand, the conventional trains only lose 2 $\mathrm{mph}$ in crashworthy speed, from $12 \mathrm{mph}$ to $10 \mathrm{mph}$, with the additional weight. At the heaviest weight, the CEM train has a higher crashworthy speed by $18 \mathrm{mph}$.

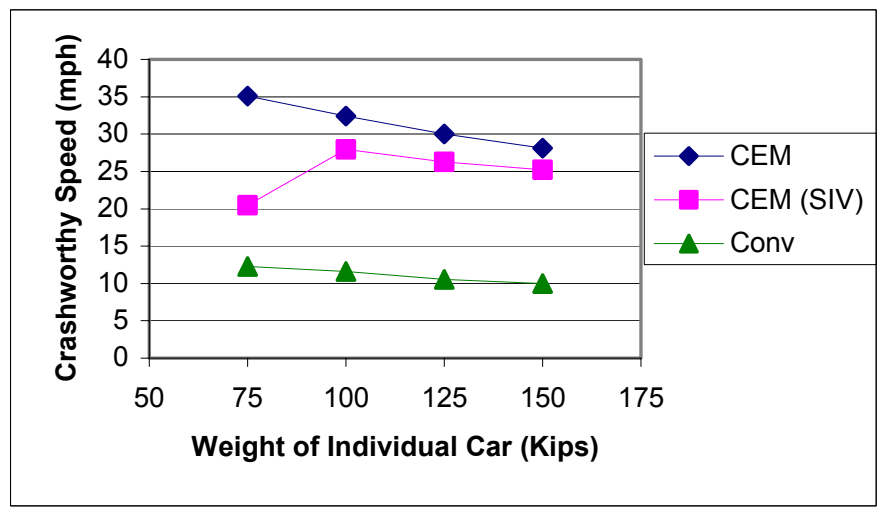

Figure 6. The effect of car weight on the crashworthy speed for push-pull trains

The second factor is measuring a crashworthy speed in the secondary impact velocity (SIV). In conventional train collisions, fatalities due to crush occur at low train velocities and therefore the SIV is not a factor. In the CEM trains however, SIV does have to be taken into account. The SIV lowers the maximum crashworthy speed by $15 \mathrm{mph}$ in the 75 
Kip car. The lightest car feels the most severe decelerations during the crash, so the passengers are thrown forward more violently. In the heavier cars, the SIV again lowers the crashworthy speed, but by a lesser degree. Even when SIV is taken into account, the maximum crashworthy speed for CEM trains $(20 \mathrm{mph})$ is still higher than the maximum crashworthy speed for conventional trains (12 mph).

Now that both car weight and train length have been discussed separately, it is useful to put all this information together for the push-pull consists. In the graph shown in Figure 7, the weight versus crashworthy speed graph has been expanded to show the results for the three different train lengths. This graph can be used to highlight some of the trends discussed earlier.

In the CEM trains, the length of a consist is not an influential variable. Car weight however, does affect the crashworthy speed of CEM cars. When looking at crashworthy speed due to SIV, car length again has no influence. Car weight has an interesting effect on the crashworthy speed due to SIV. The lightest cars have dramatically lower crashworthy speeds. At the 100 Kip mark however, the crashworthy speed increases and then falls to a smaller degree in the heavier cars.

With the conventional consist, train length plays a greater role than car weight, although both affect crashworthiness. For each weight, increasing the train length lowers the crashworthy speed. Increasing the train length increases the kinetic energy of the train prior to the collision. The differences in energy dissipation will be explored later in this paper.

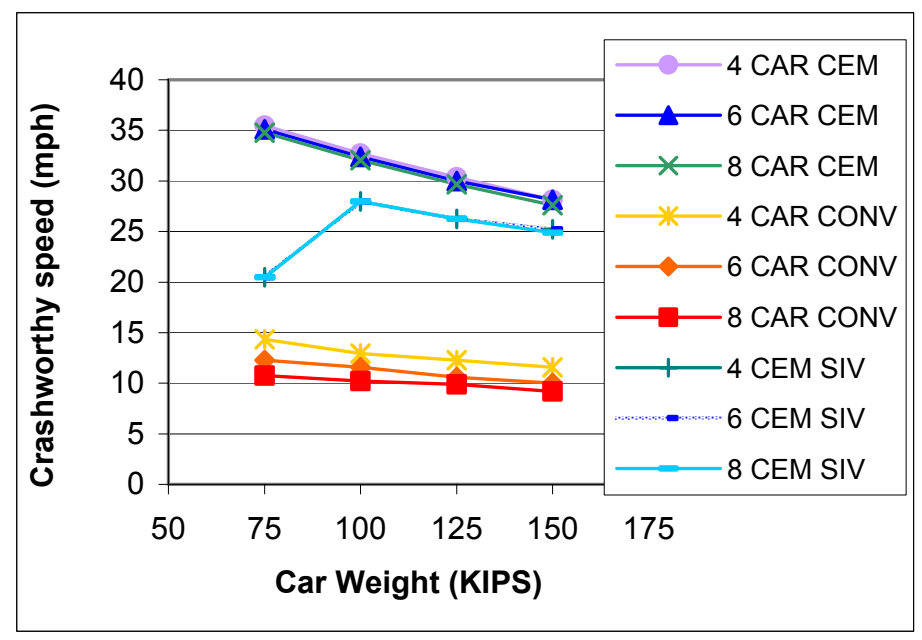

Figure 7. Crashworthy speed as a function of car weight, for 4,6 , and 8 car conventional and CEM trains

\section{Multiple Unit Trains}

Multiple Unit (MU) trains are passenger trains in which each car has an individual engine. This eliminates the need for a separate locomotive car. As part of the complete study on the effects of CEM consists, MU trains have been studied separately from push-pull trains. In a train with the same amount of passenger cars, MU trains have lower kinetic energy because they lack a heavy locomotive. In general, MU trains have a higher maximum crashworthy speed than their push-pull train counter parts. Table 4 shows the operational variables used in this study.
Table 4. Analysis Matrix for MU Trains

\begin{tabular}{|c|c|}
\hline Factor & Variations \\
\hline Train Type \#2 & MU \\
\hline Train Length & 2,4, or 6 Coach Cars \\
\hline Car Weight & $75,100,125$, or 150 Kips \\
\hline
\end{tabular}

\section{MU Trains: Consist Length}

The examination of the crashworthiness of MU trains begins by looking at train length. In this example, weight is being held constant at 100 Kips. The lengths analyzed are shown in Table 5.

Table 5. Analysis Matrix for MU trains with varying lengths

\begin{tabular}{|c|c|c|}
\hline $\begin{array}{c}\text { Consist } \\
\text { Length }\end{array}$ & \multicolumn{2}{|c|}{ Consist Make-up } \\
\hline 3 Car MU: & 1 Cab Car & 2 Coach Cars \\
\hline 5 Car MU: & 1 Cab Car & 4 Coach Cars \\
\hline 7 Car MU: & 1 Cab Car & 6 Coach Cars \\
\hline
\end{tabular}

In the MU trains, the conventional consists experience a greater change in crashworthy speed than the CEM consists with varying lengths. Once again, the trend is that longer trains have lower crashworthy speeds than shorter trains. Although the crashworthy speed for CEM trains is much greater than the crashworthy speed for conventional trains, they seem to be similarly affected by change in consist length. The three car CEM consist has a crashworthy speed of $35 \mathrm{mph}$, while the 7 car consist has a $32 \mathrm{mph}$ crashworthy speed. This gives the CEM train a drop of $3 \mathrm{mph}$ in crashworthy speed with the addition of 4 cars. The conventional train drops $5 \mathrm{mph}$ in maximum crashworthy speed, from 17 to $12 \mathrm{mph}$ with the addition of 4 cars. In both the CEM and the conventional train cases, the MU consists react more strongly to increase in length than their push-pull train counter parts. When looking at the secondary impact velocity (SIV) in the MU consists, the shorter MU trains experience a large drop in crashworthy speed. For the short MU consists, making the train a CEM does not alone make a large improvement in passenger safety. In these cars, the interior of the car should be modified to decrease fatalities due to SIV. The results for length variations are shown in Figure 8.

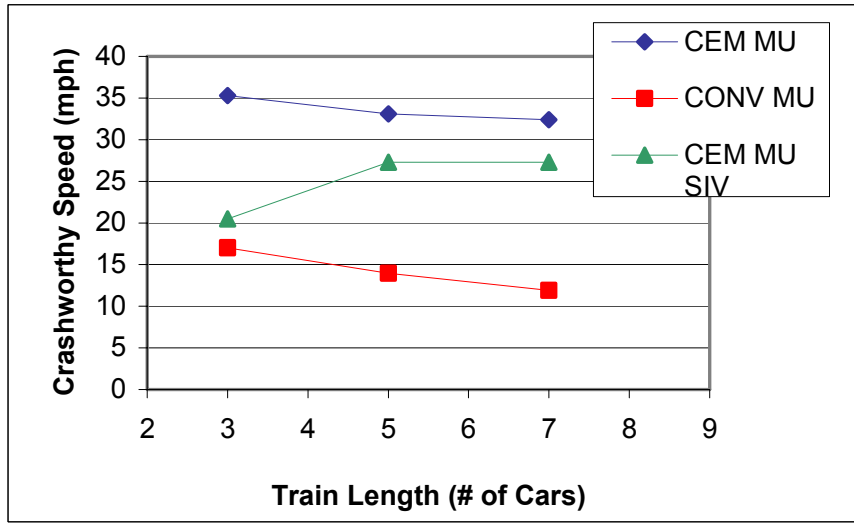

Figure 8. Maximum Crashworthy speed as a function of car length for MU trains 


\section{MU Trains: Consist Weight}

The effect of consist weight on MU trains are examined for CEM and conventional train structure. As in the push-pull consists, four different weight variations are used with the MU trains. The individual cars were run at $75,100,125$, and 150 Kips. To simplify the results, the consist length is held constant at 5 cars. In these results, shown in Figure 9, it is clear that weight has an effect on the crashworthiness of trains. When looking at crashworthy speed due to crush, the CEM consists see a drop of $10 \mathrm{mph}$ in crashworthy speed, from $38 \mathrm{mph}$ to 28 $\mathrm{mph}$, when the weight is increased. The conventional consist sees a drop of $5 \mathrm{mph}$ in crashworthy speed, from $17 \mathrm{mph}$ to 12 $\mathrm{mph}$, with the same increase in weight. Even with the dramatic loss in crashworthy speed in the CEM trains, passengers are still safer in the CEM consist. At an equal velocity and train length, heavier cars have a higher kinetic energy. As anticipated, the heavier cars have a lower crashworthy speed than the lighter cars.

When taking the SIV into account, we see a similar trend as we saw in the train length examples. The trains with the lightest cars have a much lower crashworthy speed when SIV is accounted for. When the car weight is increased to $100 \mathrm{kips}$, the difference between crashworthy speed due to crush and crashworthy speed due to SIV decreases. In lighter cars, a CEM train will be much more effective if SIV can be lowered, possibly by rear facing seats or seatbelts.

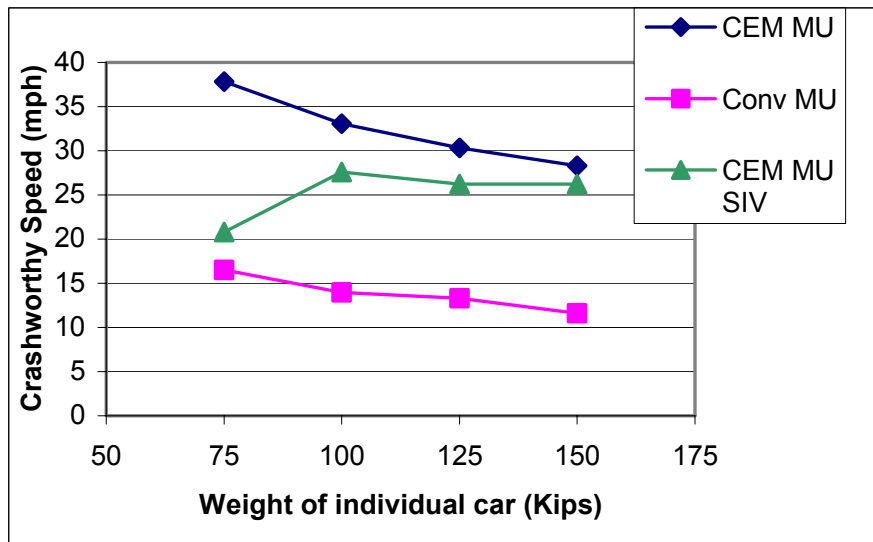

Figure 9. The Effect of car weight on crashworthy speed for an MU train

The weight and length variations were expanded to show a large range of possibilities for MU trains. These results are shown in Figure 10. In MU trains, car length and car weight have greater effects on crashworthy speed than they had an effect on push-pull trains. MU trains start out with less kinetic energy than push-pull trains, because the weight of the locomotive is so high. Adding 25 kips to the MU train cars has a greater effect on the overall weight. Likewise, adding two more cars increases the kinetic energy of the MU train more than it affects the push-pull train. In the lighter MU trains, there is a greater danger of SIV fatalities. Doing something to lower the SIV, such as putting rear-facing seats in the cab car, can help this problem.

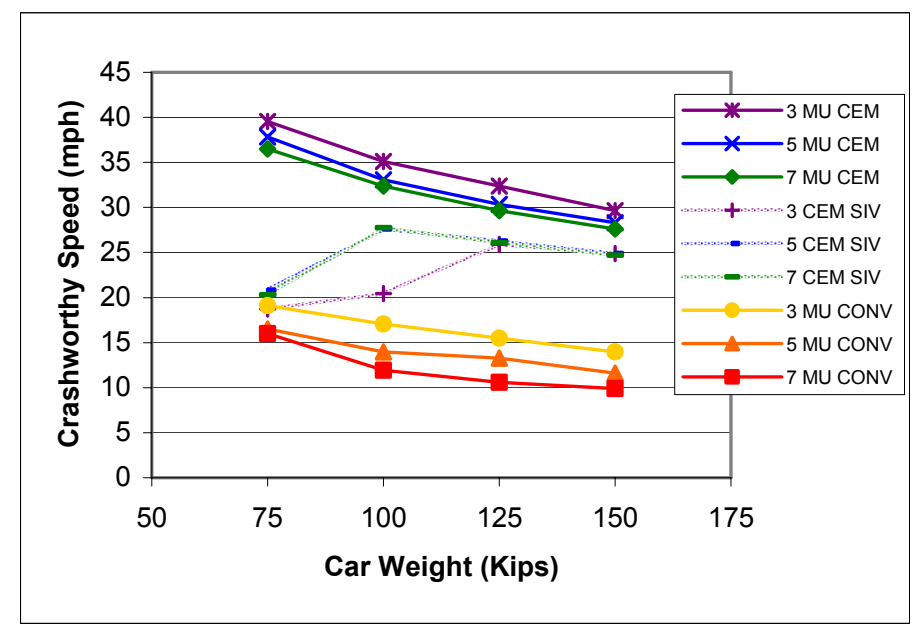

Figure 10. Crashworthy speed as a function of train length and car weight for a MU train

\section{SUMMARY AND CONCLUSIONS}

The simulation results show that a CEM train has a higher crashworthy speed than a conventional train for all of the train parameters considered - car weight, train length, and MU and push-pull trains.

The CEM and conventional trains react differently to increases in train length or car weight. Varying the length of the push-pull train has a greater effect on conventional trains. Crashworthy speed decreases for the conventional train, as the train gets longer. Crashworthy speed also decreases for the $\mathrm{CEM}$ train as it gets longer, but not as rapidly as for the conventional train. When cars are added to a CEM train, there is the benefit of additional crush zones on the ends of the additional cars, but there is the negative effect of the added weight. The safety increase of adding crush zones balances out the safety decrease of adding more kinetic energy. The crashworthy speed of CEM trains is only slightly affected by train length.

Car weight has a greater influence on CEM trains than on conventional trains. Crashworthy speed decreases for CEM trains as the car weight increases. Crashworthy speed also decreases for conventional trains as car weight increases, but not as rapidly. When weight is added to a CEM train, kinetic energy is increased without adding additional area for energy absorption. In the case of adding weight to a CEM train, heavier trains have a lower crashworthy speed because they have more kinetic energy to dissipate, but the same capacity to dissipate energy in the crush zones.

MU trains follow the same trends that push-pull trains follow. MU trains are lighter due to the lack of a locomotive, and as a result have overall higher crashworthy speeds than the push-pull trains.

The study results presented in this paper, in combination with the study results presented in $[2,3]$, show that CEM cars can be introduced into service with minimum risks and with great potential benefit. Previous studies have shown that the crashworthiness performance of a consist which is a mix of conventional and CEM equipment is never worse than the performance of an all conventional equipment consist in a trainto-train collision, and is always better when a CEM car is the impacting cab car. The results of this study show that crush 
zones are beneficial for both MU and push-pull service, and that CEM makes train crashworthiness nearly independent of train length, for the range of train lengths typically used in passenger service.

The maximum crashworthy speed of a CEM train decreases as car weight increases, if the crush zone and the amount of energy it can absorb remains constant. This result suggest that increasing amount energy absorbed by the crush zone may be necessary to offset additional car weight.

\section{ACKNOWLEDGEMENTS}

This work was performed as part of the Equipment Safety Research Program sponsored by the Office of Research and Development of the Federal Railroad Administration. The authors would like to thank Tom Tsai, Program Manager, and Claire Orth, Division Chief, Equipment and Operating Practices Research Division, Office of Research and Development, Federal Railroad Administration, for their support.

\section{REFERENCES}

[1] Tyrell, D.C., Severson, K.J., Marquis, B.J., "Crashworthiness of Passenger Trains", US Department of Transportation, DOT/FRA/ORD-97/10, 1998.

[2] Tyrell, D.C., Perlman, A.B., "Evaluation of Rail Passenger Equipment Crashworthiness Strategies," Transportation Research Record No. 1825, pp. 8-14, National Academy Press, 2003.

[3] Severson, K., Tyrell, D., Perlman, A.B., "Analysis of Collision Safety Associated with Conventional and Crash Energy Management Cars Mixed Within a Consist," American Society of Mechanical Engineers, Paper No. IMECE200344122, November 2003.

[4] Tyrell, D.C., A Rubin, editors, "Proceedings of the Symposium on Rail Vehicle Crashworthiness, June 1996", US Department of Transportation, DOT/FRA/ORD-97/08, 1998.

[5] Tyrell, D., Severson, K., Perlman, A.B., "Single Passenger Rail Car Impact Test Volume I: Overview and Selected Results," US Department of Transportation, DOT/FRA/ORD00/02.1, March 2000.

[6] Tyrell, D., "Passenger Rail Train-to-Train Impact Test Volume I: Overview and Selected Results," US Department of Transportation, DOT/FRA/ORD-03/17.I, July 2003.

[7] Parent, D., Tyrell, D., Perlman, A.B., "Crashworthiness Analysis of the Placentia, CA Rail Collision," Proceedings of ICrash 2004, International Crashworthiness Conference, San Francisco, California, July 14-16, 2004. 